\title{
PENGARUH WAKTU CURING TERHADAP STABILITASI TANAH DASAR LEMPUNG MENGGUNAKAN POLIMER
}

\author{
Annisa Putri Adriza ${ }^{1}$, Luky Handoko ${ }^{2 *}$ dan John Tri Hatmoko ${ }^{3}$ \\ ${ }^{1,2,3}$ Program Studi Teknik Sipil, Fakultas Teknik, Universitas Atma Jaya Yogyakarta \\ *Corresponding author, e-mail: luky.handoko@uajy.ac.id
}

\begin{abstract}
ABSTRAK
Tanah lempung lunak tersebar di beberapa wilayah di Indonesia. Umumnya, tanah lempung lunak sifat mekanik yang buruk sehingga tidak cocok digunakan sebagai tanah dasar. Stabilisasi terhadap lapisan tanah dasar untuk pembangunan jalan merupakan salah satu solusi untuk mengatasi masalah yang terjadi pada tanah lunak. Polimer adalah bahan tambah masih dikembangkan untuk stabilisasi tanah dasar di Indonesia. Polimer memiliki potensi menggantikan semen dan kapur sebagai bahan tambah tradisional. Pada penelitian ini akan dibahas mengenai pengaruh waktu curing terhadap sifat fisik tanah dan sifat mekanik tanah dasar yang distabilisasi oleh polimer bila dibandingkan dengan tanah asli. Benda uji diperam selama 2, 4, 6, 9, 18, 24, 48, 72 jam dan 7 hari. Hasil penelitian menunjukkan adanya perbaikan dengan menurunnya nilai indeks plastisitas dan kadar air. Nilai kuat tekan bebas mengalami kenaikan sebesar $10 \%$ setelah di lakukan pemeraman selama 7 hari.
\end{abstract}

Kata Kunci : Tanah dasar, waktu curing, polimer, indeks plastisitas, kuat tekan bebas

\section{PENDAHULUAN}

Stabilisasi tanah dasar untuk pembangunan jalan adalah salah satu solusi untuk mengatasi masalah berbagai macam jenis tanah yang ada di Indonesia. Stabilisasi tanah adalah cara untuk memperbaiki sifat-sifat tanah, ada berbagai macam cara yang dapat dilakukan untuk stabilisasi tanah. Salah satunya adalah stabilisasi kimiawi yaitu mencampur tanah dengan bahan kimia, semen dan kapur umumnya digunakan sebagai bahan tambah untuk peningkatan kekuatan tanah. Saat ini banyak bahan tambah aditif yang sedang berkembang untuk membantu stabilsasi tanah.

Polimer adalah bahan tambah yang masih jarang digunakan untuk stabilisasi lapisan tanah dasar di Indonesia. Studi mengenai hal ini pun masih langka di Indonesia. Penambahan polimer dapat membantu memperbaiki sifat tanah dasar yang dapat di terapkan dalam perencanaan pembangunan dan perbaikan jalan. Waktu yang dibutuhkan untuk polimer bereaksi merupakan hal yang perlu di perhatikan dalam stabilisasi tanah, sehingga saat pengerjaan di lapangan akan lebih efisien. Polimer bisa mencegah erosi, mitigate surficial slope failure, mengurangi kerusakan pavement, menstabilisasi tanah dasar hingga membangun jalan tak beraspal, Sauceda M,dkk, 2014.

Penelitian tentang stabilisasi tanah menggunakan polimer telah dilakukan sebelumnya. Menurut Moustafa,dkk,1997 menyimpulkan bahwa kekuatan bertambah seiring dengan bertambahnya waktu curing hal ini terjadi dikarenakan proses kondensasi yang merupakan hasil dari interaksi kimia antara material polimer dan butiran tanah. Menurut Georgees,dkk, 2018, aditif stabilisasi polimer menunjukkan karakteristik peningkatan kekuatan dan ketahanan dari tanah disamping itu juga memiliki keuntungan 
lower carbon footprint dibandingkan dengan zat stabilisasi yang tradisional. Menurut Rodriguess,dkk,2018, Polyampholyte Polymer sebagai bahan stabilisasi untuk tanah dasar. Hasil penelitian tersebut menunjukkan beberapa tipe polimer merupakan binder yang bagus dan hasil performanya lebih unggul daripada semen Portland. Pengaruh dari liquid acrylic polymer terhadap sifat geoteknik tanah berbutir halus telah diteliti,Kolay,dkk,2016, Polimer bekerja dengan memberikan lapisan pada partikel tanah dan untuk struktur berlapis polimer tidak bisa melapisi dengan cukup sehingga terjadi penambahan kuat tekan bebas dengan penambahan polimer.

Menurut Naeni S,A,dkk,2012, yang menggunakan tanah lempung lunak yang distabilisasi oleh waterbone polymer. Penelitian ini menunjukkan bahwa properti tanah yang di stablisasi menggunakan polimer dengan waktu curing memiliki hasil yang meningkat. Kesimpulan dari penelitian ini adalah curing time yang optimum adalah 8 hari dan berdasarkan sudut pandang mekanik dan penerapan untuk jalan waktu curing tersebut merupakan skema yang layak dan ekonomis.

Menurut Kolay,P,K,dkk,2012, sample di curing selama 7, 14 dan 28 hari pada ruangan terbuka. Hasil penelitian ini menunjukkan nilai UCS pada sample yang di persiapakan dengan OMC diruangan terbuka meningkat dari 30\% sampai 75\% sedangkan pada ruangan tertutup UCS meningkat hanya 12\% hingga 14\%. Menurut Ates,2013, setelah curing 7 hari tanah yang distabilisasi oleh polimer sudah mencapai $90 \%$ dari kekuatan curing 14 hari.

\section{TUJUAN PENELITIAN}

Tujuan dari penelitian ini adalah untuk mempelajari pengaruh penambahan polimer pada indeks plastisitas dan kuat tekan bebas tanah lempung yang dicampur dengan polimer. Hasil tersebut dibandingkan dengan tanah asli yang/dipadatkan. Pengujian dilakukan pada waktu yang relatif cepat, yaitu kurang dari 7 hari.

\section{METODE PENELITIAN}

Metode yang digunakan dalam penelitian ini adalah studi eksperimental yaitu dengan melakukan percobaan langsung di laboratorium. Penelitian ini menggunakan 2 jenis polimer dengan perbandingan polimer A: polimer B: air yaitu 1:1:200. Benda uji akan dibuat dengan diameter $5 \mathrm{~cm}$ dan tinggi $10 \mathrm{~cm}$. Tanah dasar lempung yang sudah di stabilisasi oleh polimer diuji setelah curing 2 jam, 4 jam, 6 jam, 9 jam, 18 jam, 24 jam, 48 jam, 72 jam dan 7 hari.

Tanah yang dibutuhkan merupakan tanah lempung yang memiliki nilai CBR lapangan kurang dari 3 karena termasuk golongan tanah dasar yang sangat buruk (very poor subgrade). Sampel tanah diambil dari lapangan lalu direndam selama 4 hari dan dilakukan pengujian CBR di laboratorium. Sebelum memulai penelitian dilakukan pengujian terhadap tanah asli agar mengetahui sifat-sifat tanah asli. Pengujian yang di lakukan sesuai dengan standar ASTM antara lain; kadar air, ASTM D2216-98, berat jenis, ASTM D85402, analisa saringan, ASTM D422-63, batas-batas Atterberg, ASTM D4318-00, pemadatan, ASTM D698-12e2, kuat tekan bebas,ASTM D2166-00. 
Mixing dilakukan terlebih dahulu sebelum dilakukan pengujian benda uji. Tanah yang digunakan merupakan tanah lempung kering yang lolos saringan No.40, lalu dilakukan penambahan air dan polimer pada tanah. Mixing dilakukan untuk tanah lempung yang di padatkan dengan kadar air optimum dan tanah lempung dengan polimer sesuai perbandingan yang sudah ditentukan.

Pengujian sifat fisik tanah dilakukan setelah benda uji yang telah dicampur polimer dilakukan pemeraman selama 24, 48, 72 dan 7 hari. Pengujian sifat fisik yang dilakukan adalah kadar air,ASTM D2216-98, dan batas-batas atterberg,ASTM D4318-00 Pengujian sifat mekanik tanah yaitu uji kuat tekan bebas, ASTM D2166-00, setelah benda uji yang dicampur polimer dilakukan pemeraman selama 2, 4, 6, 9, 18, 24, 48, 72 jam dan 7 hari.

\section{HASIL DAN PEMBAHASAN}

\section{Parameter Fisik Tanah Asli}

Sample tanah diuji di Laboratorium Mekanika Tanah, Universitas Atma Jaya Yogyakarta. Tanah diambil dari Klaten,Yogyakarta. Dari hasil penelitian, tanah dasar lempung yang digunakan memiliki karakteristik seperti didapat dalam Tabel 1.

Tabel 1. Hasil pengujian parameter tanah asli

\begin{tabular}{|l|l|l|}
\hline No & \multicolumn{1}{|c|}{ Parameter Tanah } & Hasil Pengujian \\
\hline 1 & Kadar air $(w)$ & $42,4 \%$ \\
\hline 2 & Berat jenis $(G)$ & 2,4 \\
\hline 3 & Batas Cair $(L L)$ & $76,3 \%$ \\
\hline 4 & Batas Plastis $(P L)$ & $52,9 \%$ \\
\hline 5 & Batas Susut $(S L)$ & $15 \%$ \\
\hline 6 & Indeks Plastik $(I P)$ & $23,4 \%$ \\
\hline 7 & Klasifikasi ASTM [14] & OH \\
\hline 8 & Klasifikasi AASHTO [15] & A-7-6 \\
\hline
\end{tabular}

Kadar air tanah asli (w) sebesar 49,5\%. Kadar air ini merupakan rata-rata dari 2 tinbox dimana tinbox 1 sebesar 43,4\% dan tinbox 2 sebesar 41,5\%. Untuk pengujian berat jenis tanah didapatkan hasil sebesar 2,4. Hasil pengujian diperoleh nilai batas cair sebesar $76,3 \%$ dan batas plastis diperoleh nilai sebesar 52,9\%. Indeks plastisitas didapatkan dari selisih antara batas cair dengan batas plastis maka di dapatkan nilai sebesar 23,4\%. Pengujian batas susut juga dilakukan dan diperoleh nilai sebesar 14,9\%.

Pengujian butiran tanah (grain size analysis) terdiri dari pengujian hydrometer dan pengujian saringan. Dengan menganalisa kurva pada Gambar 1 didapatkan susunan butir tanah kerikil (gravel) sebesar 0\%, pasir (sand) sebesar 15,3\%, lanau (silt) sebesar 59,7\% dan lempung (clay) sebesar 25,2\%.

Menurut sistem klasifikasi tanah Unified Soil Classification System (USCS), ASTM D2487-00,2010 apabila berat sampel lolos ayakan No.200 lebih dari 50\% maka tanah dapat digolongkan berbutir halus. Hasil analisa saringan untuk sample tanah ini 
menunjukkan bahwa tanah yang lolos saringan no.200 sebesar 84,9\% maka tanah tergolong berbutir halus.

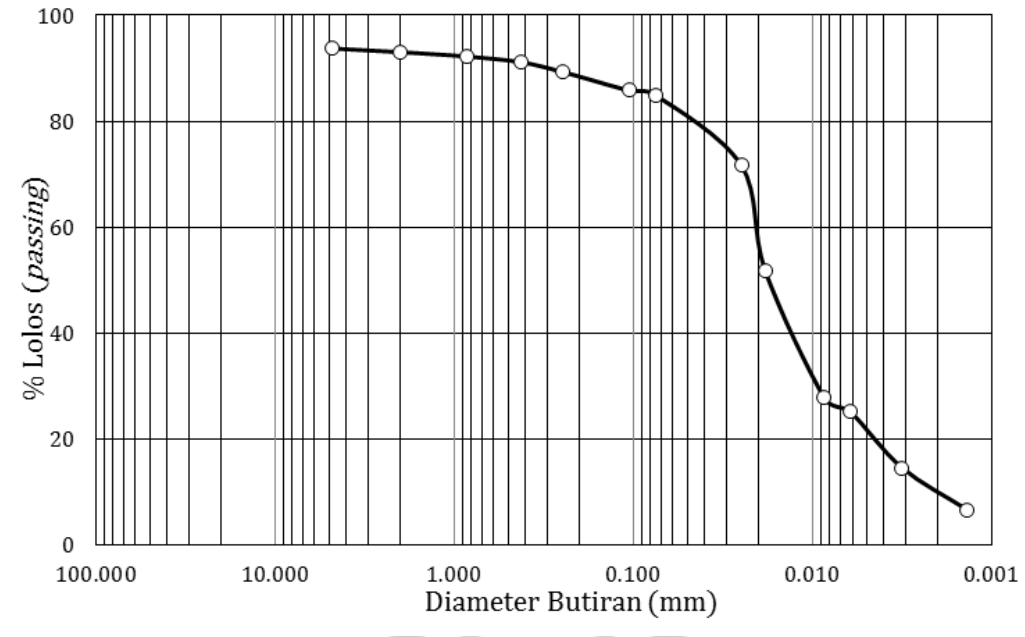

Gambar 1. Distribusi Ukuran Butiran Tanah

Menurut ASTM D2487-00,2010,Tanah yang digunakan dalam penelitian ini bisa diklasifikasikan sebagai organic soil dimana biasanya memiliki warna coklat tua hingga hitam dan memiliki bau organik. Tanah organik biasanya akan berubah warna menjadi warna yang lebih muda ketika di keringkan. Warna tanah yang digunakan pada penelitian ini bisa di lihat pada Gambar 2, dimana tanah berwarna hitam dan setelah dikeringkan berubah warna menjadi lebih muda. Tanah organik biasanya tidak memiliki high toughness atau plastisitas yang tinggi. Tanah yang digunakan dalam penelitian ini ketika pengujian batas plastis masih termasuk mudah untuk digulung dan tidak membutuhkan waktu yang lama untuk mencapai batas plastisnya maka dari itu tanah ini termasuk tanah dengan plastisitas medium. High toughness ditunjukkan pada saat pengerjaan batas plastis membutuhkan tekanan yang tinggi untuk menggulung tanah agar mencapai batas plastisitas, sedangkan untuk tanah yang digunakan pada penelitian ini hanya membutuhkan tekanan yang sedang sehingga tergolong medium toughness.

Menurut ASTM D2487-00,2010 tanah yang lolos saringan No.200 apabila lebih dari $50 \%$ termasuk golongan fine-grained soils dan tanah yang memiliki batas cair sama dengan atau lebih dari 50 termasuk golongan organic dan memiliki berat jenis sebesar 2,4 maka dari itu tanah yang digunakan pada penelitian ini termasuk golongan organic clay $(\mathrm{OH})$.
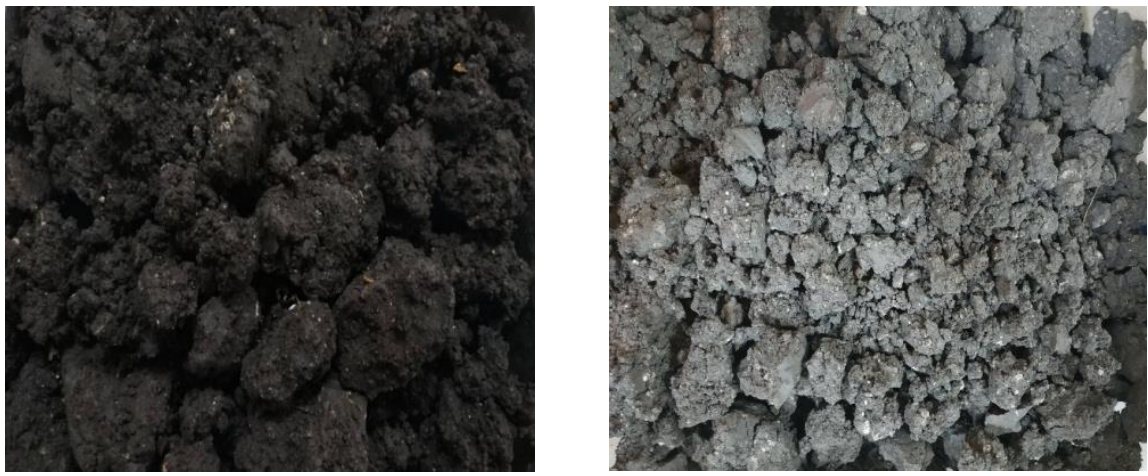

Gambar 2. Tanah dasar lempung 


\section{Pengujian Pemadatan Standar Proctor}

Standard Proctor Test dilakukan untuk mendapatkan dua hasil yaitu berat kering maksimum (MDD) dan kadar air optimum (OMC). Pengujian pemadatan dilakukan dengan mencampur tanah asli dengan penambahan air bervariasi pada masing-masing campuran tanah. Pemadatan tanah dapat didefinisikan sebagai proses naiknya kerapatan tanah dengan memperkecil jarak antar partikel, sehingga mempengaruhi pori-pori udara yang berada diantara butiran-butiran tanah. Pada uji pemadatan akan didapatkan kurva berat volume kering dengan kadar seperti pada Gambar 3 di dapatkan kadar air optimum (OMC) sebesar 27\% dan berat kering tanah maksimum (MDD) $1.50 \mathrm{gram} / \mathrm{cm}^{3}$.

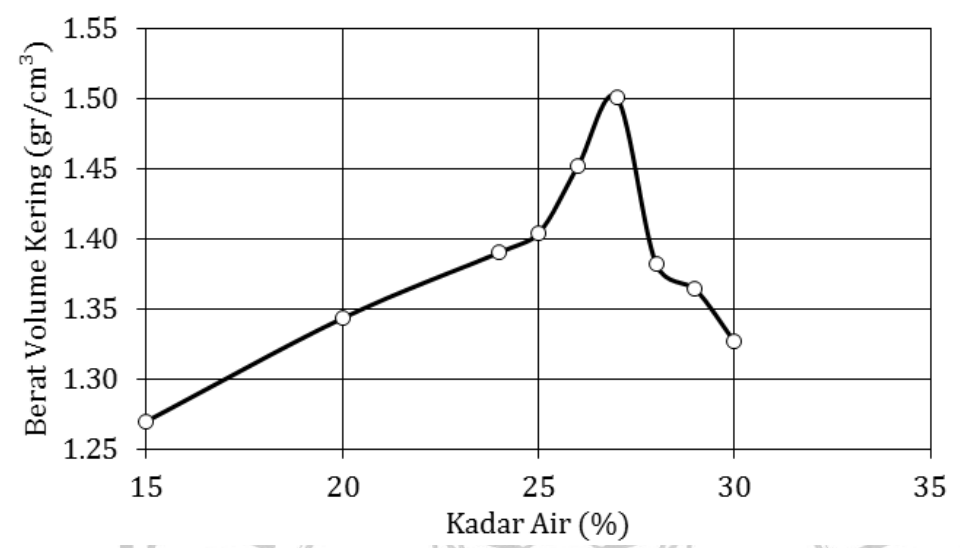

Gambar 3. Grafik Pemadatan Tanah

\section{Perhitungan Polimer}

Perhitungan polimer pada penelitian ini menggunakan perbandingan yang direkomendasikan oleh perusahaan perbandingan polimer A: polimer B: air yaitu 1:1:200. Dengan OMC 27\%, maka pada tanah 3,5 kg digunakan polimer sebanyak 4,67 gram untuk masing-masing polimer dan air sebanyak 935,64 gram. Perbandingan tersebut digunakan pada seluruh campuran uji laboratorium.

\section{Pengaruh Waktu Curing terhadap Indeks Plastisitas Tanah}

Pengujian yang dilakukan terhadap pencampuran tanah asli dan polimer adalah pengujian batas cair (LL) dan plastis (PL) yang bertujuan untuk melihat pengaruh polimer dan waktu pemeraman terhadap indeks plastistitas (IP). Tabel 2 menunjukkan hasil uji laboratorium uji batas cair (LL) dan batas plastis (PL).

Tabel 2. Batas Cair, Batas Plastis, Indeks Plastisitas dengan Polimer

\begin{tabular}{|c|c|c|c|c|}
\hline \multirow{2}{*}{ Material } & $\begin{array}{c}\text { Watku } \\
\text { Curing }\end{array}$ & $\begin{array}{c}\text { Batas Cair } \\
(\text { LL })\end{array}$ & $\begin{array}{c}\text { Batas Plastis } \\
(P L)\end{array}$ & $\begin{array}{c}\text { Indeks Plastis } \\
(P I)\end{array}$ \\
\hline Tanah Asli & - & 76,9 & 52,9 & 23,4 \\
\hline \multirow{3}{*}{ Tanah + Polimer } & 24 Jam & 85,9 & 44,2 & 41,7 \\
\cline { 2 - 5 } & 48 Jam & 74,8 & 43,5 & 31,3 \\
\cline { 2 - 5 } & 72 Jam & 68,3 & 37,4 & 30,9 \\
\cline { 2 - 5 } & 7 Hari & 74,4 & 41,8 & 32,6 \\
\hline
\end{tabular}


Berdasarkan Gambar 4 bahwa semakin lama waktu curing batas cair dan batas plastis tanah yang di campur dengan polimer semakin menurun. Sehingga indeks plastisitas pun menurun semakin lama waktu curing. Terlihat pada Tabel 3 dan Gambar 4 indeks plastistitas mengalami peningkatan ketika tanah sudah di campur dengan polimer dari 23,4\% untuk tanah asli menjadi 32,6\% untuk tanah yang dicampur oleh polimer dengan curing 7 hari.Penelitian yang dilakukan oleh [6] menyimpulkan bahwa indeks plastisitas memiliki pengaruh terhadap nilai kuat tekan bebas, dimana apabila terdapat kenaikan pada nilai indeks plastisitas maka akan terjadi penurunan dalam nilai kuat tekan bebas.

Pada Gambar 5 bisa di lihat bahwa kadar air juga mengalami penurunan. Kadar air menurun karena reaksi polimer mengakibatkan pemecahan emulsi polimer dan kehilangan air karena evaporasi, Naeni,S.A, dkk, 2012. Hal ini menunjukkan bahwa kehilangan kadar air merupakan salah satu pengaruh dari turunnya nilai indeks plastisitas. Penurunan indeks plastisitas menunjukkan perbaikan yang terjadi pada tanah yang dicampur dengan polimer.

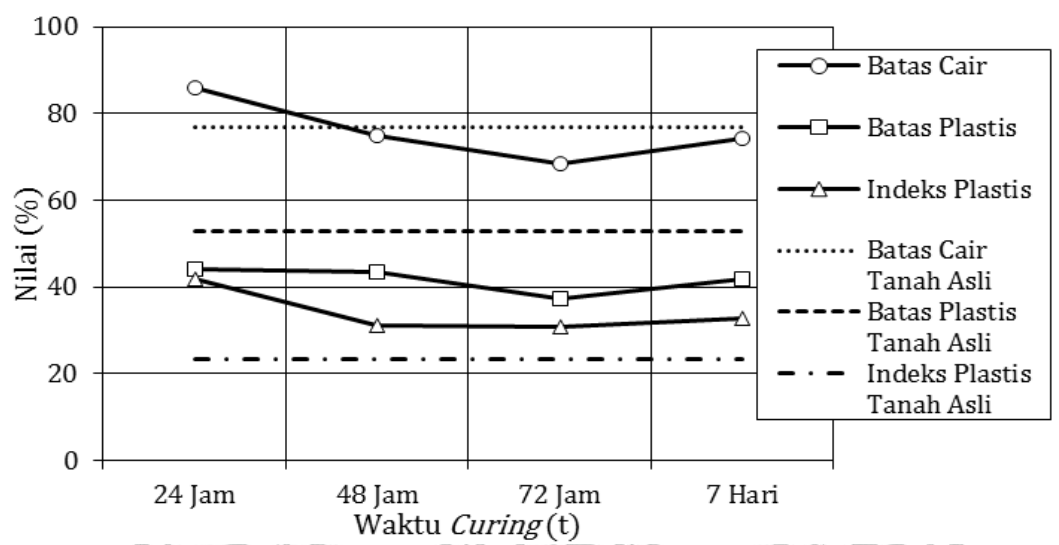

Gambar 4. Hubungan antara Batas Plastis, Batas Cair dan Indeks Plastisitas terhadap waktu curing

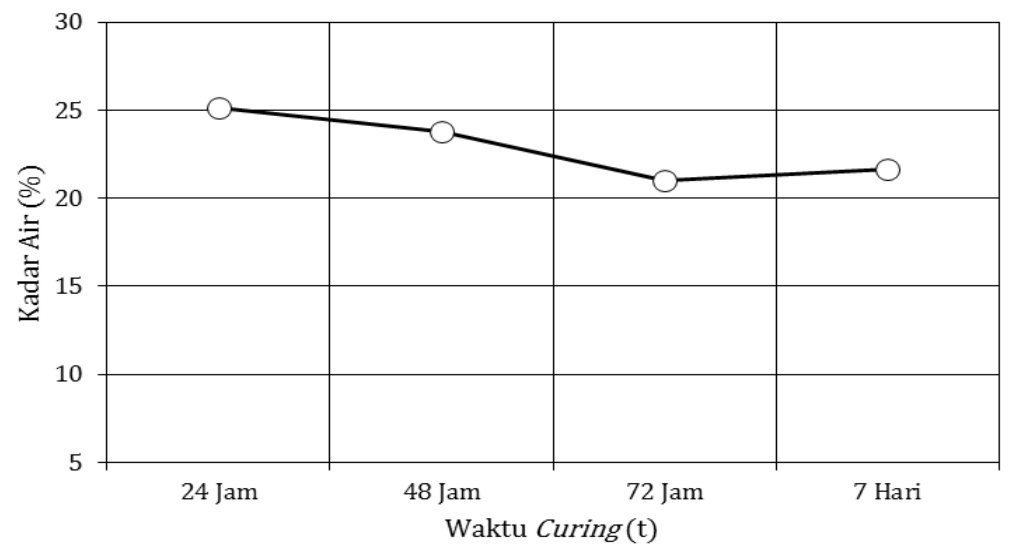

Gambar 5. Grafik Kadar Air terhadap Waktu Curing

Menurut Naeni,S,A,2010, polimer memiliki keunggulan karena polimer tidak kehilangan kadar air sebanyak semen. Semen cenderung kehilangan kadar air yang lebih besar dikarenakan reaksi hidrasi yang terjadi dan menganggu performa dan kemampuan untuk mengontrol kualitas dari lapisan subgrade yang sudah di stabilisasi. 


\section{Pengaruh Waktu Curing terhadap Kuat Tekan dan Modulus Elastisitas Tanah}

Pengujian tekan bebas di lakukan untuk menentukan kuat tekan bebas tanah kohesif. Pemeriksaan kuat tekan bebas dapat dilakukan pada tanah asli atau tanah padat buatan. Hasil uji tekan bebas untuk curing 2 jam bisa dilihat pada Gambar 6.

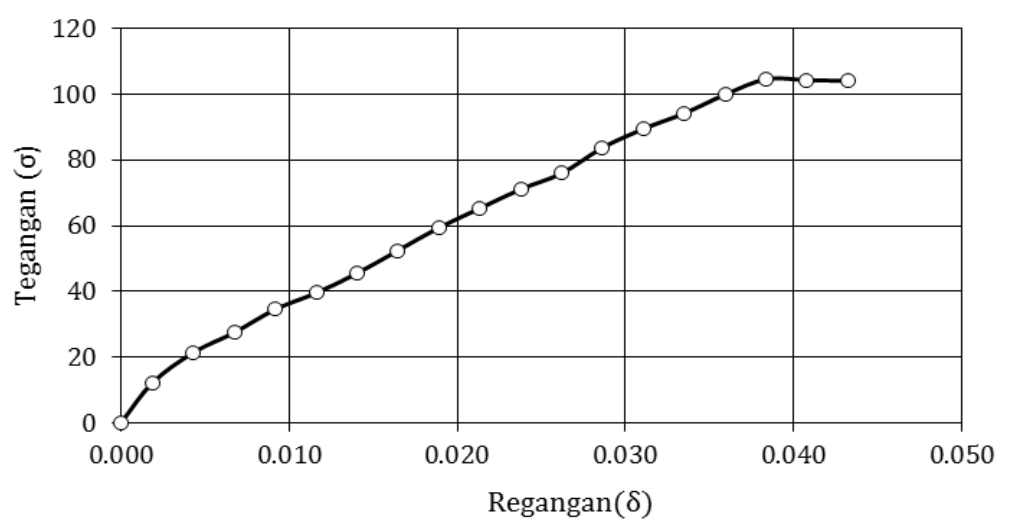

Gambar 6. Grafik Kuat Tekan Bebas dengan Waktu Curing 2 Jam

Berdasarkan Tabel 3 dari hasil pengujian dapat dilihat bahwa semakin lama waktu curing maka terjadi kenaikan nilai kuat tekan bebas. Pada Gambar 7 terjadi kenaikan nilai kuat tekan bebas dari $85,6 \mathrm{kPa}$ untuk tanah asli menjadi $121,1 \mathrm{kPa}$ untuk tanah yang di stabilisasi oleh polimer dengan waktu curing 7 hari. Prosentase kenaikan hanya sebesar $10 \%$, menunjukkan bahwa kenaikan tidak signifikan. Hasil pengujian pada Gambar 7 menunjukkan bahwa polimer dan waktu curing memiliki pengaruh dalam peningkatan kuat tekan bebas. Kenaikan yang tidak signifikan ini bisa terjadi karena jenis dasar lempung yang digunakan, cara persiapan sample dan curing sample.

Tabel 3. Nilai Kuat Tekan Bebas terhadap waktu curing

\begin{tabular}{|c|c|c|}
\hline Tanah & Curing & Kuat Tekan Bebas $(\mathrm{kPa})$ \\
\hline Tanah Asli & - & 85,6 \\
\hline \multirow{5}{*}{ Tanah+Polimer } \\
\cline { 2 - 3 } & 2 jam & 104,5 \\
\cline { 2 - 3 } & 4 jam & 107,6 \\
\cline { 2 - 3 } & 6 jam & 115,5 \\
\cline { 2 - 3 } & 9 jam & 115,6 \\
\cline { 2 - 3 } & 18 jam & 116,6 \\
\cline { 2 - 3 } & 24 jam & 116,7 \\
\cline { 2 - 3 } & 48 jam & 118,2 \\
\cline { 2 - 3 } & 72 jam & 119,1 \\
\cline { 2 - 3 } & 7 hari & 121,1 \\
\hline
\end{tabular}

Menurut Georgees,R,N,dkk,2018, stabilisasi polimer mampu menggabungkan partikel yang berbentuk butiran lebih efektif karena permukaan area yang lebih kecil (material yang kurang halus dan memiliki kandungan lempung yang sedikit). Hal ini menunjukkan bahwa polimer tidak bekerja efektif apabila digunakan untuk jenis tanah lempung. 
Kenaikan yang tidak signifikan ini juga didapatkan pada penelitian yang di lakukan oleh, Kobay,P,K,dkk,1026, dilakukan 2 tempat curing yaitu ruang terbuka dan ruang terbatas atau tertutup. Curing ruang terbatas yang di lakukan adalah menaruh benda uji di dalam zip-lock bags, hasil curing ini hanya mendapatkan kenaikan hingga 14\% untuk nilai kuat tekan bebas. Untuk mendapatkan peningkatan kekuatan, air yang terperangkap harus terevaporasi. Penelitian ini melakukan curing dengan membungkus benda uji menggunakan plastic wrap dan di masukkan ke dalam oven maka air terhambat untuk melakukan proses ikatan dan tidak terjadi peningkatan untuk nilai kuat tekan bebas. Pada penelitian ini juga sample dipadatkan secara manual, pemadatan secara manual sehingga terjadi perbedaan pada setiap pemadatan yang dilakukan yang berpengaruh terhadap nilai kuat tekan bebas,

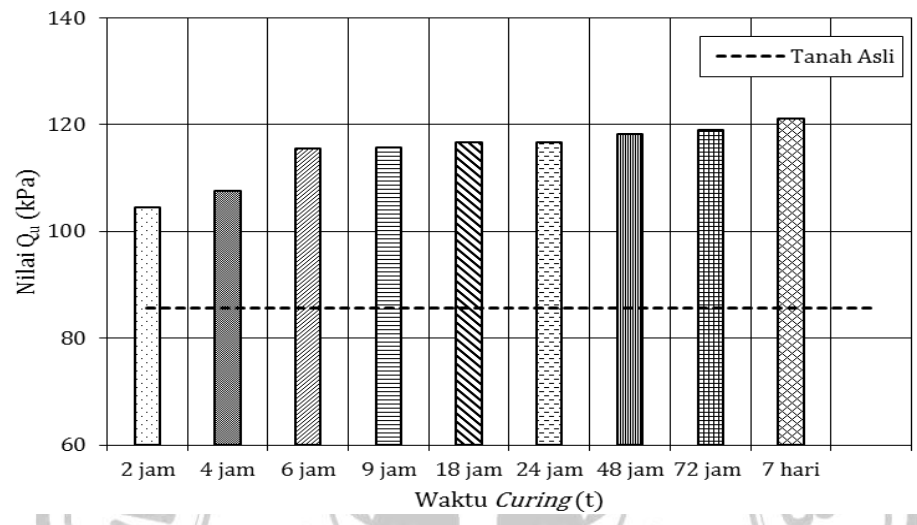

Gambar 7. Grafik Nilai Qu terhadap waktu curing

\section{Modulus Elastisitas}

Dari grafik nilai kuat tekan bebas dapat diplotkan juga untuk menentukan nilai modulus elastisitasnya. Cara penentuan nilai modulus elastisitas dapat dilakukan seperti pada Gambar 8. Gambar 8 adalah hubungan tegangan dan regangan pada tanah yang distabilisasi oleh polimer pada waktu curing 2 jam, dan cara penentuan nilai modulus elastisitasnya, didapat E50 $=3125,737 \mathrm{kPa}$. Modulus elastisitas meningkat ketika diberikan polimer. Menurut Georgees, R,N,2018, sample tanah sandy clay yang sudah dicampur polimer didapatkan hasil modulus elastisitas yang tinggi dibandingkan sample yang belum diberikan perlakuan apapun.

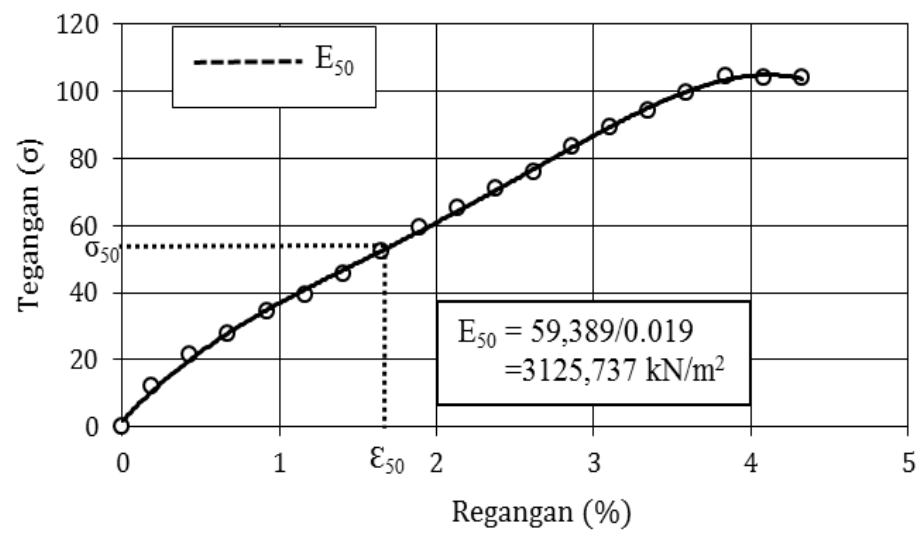

Gambar 8. Hubungan antara Tegangan dan Regangan untuk menentukan nilai modulus elastisita(E50) 
Pada Tabel 4 bisa di lihat bahwa tanah asli memiliki modulus sebesar 1130,3 kPa, saat tanah di campur dengan polimer nilai modulus elastisitas mengalami peningkatan, pada waktu pemeraman 2 jam di dapat nilai modulus $1415,8 \mathrm{kPa}$ lalu mengalami kenaikan konstasn hingga waktu curing 6 jam. Pada waktu pemeraman 9 jam didapatkan nilai modulus elastisitas sebesar 1083,1 kPa lalu mengalami kenaikan konstan hingga waktu pemeraman 72 jam dimana nilai modulus elastisitas sebesar $3139,2 \mathrm{kPa}$. Tanah yang memiliki butiran halus memiliki peningkatan modulus elastisitas yang lebih baik dibandingkan dengan tanah yang memiliki butiran halus lebih sedikit, seperti yang di lakukan oleh,Georgees R,N dkk.

Tabel 4. Nilai Modulus Elastisitas Tanah Asli dan Tanah Campuran

\begin{tabular}{|c|c|c|}
\hline Tanah & Curing & $E_{50}(\mathrm{kPa})$ \\
\hline Tanah Asli & - & 1130,3 \\
\hline \multirow{4}{*}{ Tanah + Polimer } & $2 \mathrm{jam}$ & 1415,8 \\
\cline { 2 - 3 } & $4 \mathrm{jam}$ & 1658,1 \\
\cline { 2 - 3 } & $6 \mathrm{jam}$ & $1914,4 \mathrm{j}$ \\
\cline { 2 - 3 } & $9 \mathrm{jam}$ & 1083,1 \\
\cline { 2 - 3 } & $18 \mathrm{jam}$ & 1531,3 \\
\cline { 2 - 3 } & $24 \mathrm{jam}$ & 1675,1 \\
\cline { 2 - 3 } & $48 \mathrm{jam}$ & 2329,3 \\
\cline { 2 - 3 } & $72 \mathrm{jam}$ & 3139,2 \\
\hline
\end{tabular}

Cara curing benda uji juga berpengaruh terhadap nilai modulus elastisitas, melakukan penelitian dengan curing benda uji di dalam air. Hasilnya terlihat bahwa nilai modulus elastisitas naik konstan bersama dengan nilai kuat tekan bebas. Tabel 4 menunjukkan bahwa nilai modulus elastisitas naik secara konstan ketika waktu curing 9 jam hingga 72 jam, sedangkan pada waktu curing awal mengalami peningkatan lalu mengalami penurunan.

Jenis tanah organik yang di gunakan dalam penelitian ini memiliki pengaruh terhadap kenaikan nilai kuat tekan bebas dan nilai modulus elastisitas yang tidak signifikan. Hasil ini diperkuat dengan adanya penelitian terhadap stabilisasi clayey soil menggunakan slag dan fly ash yang menyimpulkan bahwa adanya kadar organik menganggu nucleation dan pertumbuhan fase semen yang menyebabkan lambatnya peningkatan kekuatan. Studi lain menyatakan bahwa sample peat yang telah di stabilisasi dilihat dibawah mikroskop dan ditemukan bahwa hanya ada sedikit bahkan tidak ada interaksi sama sekali antara bahan stabilisasi yang terbuat selama hidrasi dan kadar organik yang ada di dalam stabilized peat.

\section{KESIMPULAN}

Pada penelitian ini, stabilisasi tanah dasar lempung dilakukan dengan menggunakan 2 jenis polimer. Secara visual tanah yang digunakan merupakan tanah organik dengan klasifikasi $\mathrm{OH}$ (lempung organik dengan plastisitas sedang sampai tinggi). Secara umum, pengaruh polimer dan waktu curing terlihat pada saat tanah dasar lempung di stabilisasi oleh polimer ditunjukkan dengan adanya penurunan kadar air, nilai batas plastis, batas cair 
dan indeks plastisitas. Kenaikan nilai kuat tekan bebas dari 85,6 kPa untuk tanah asli menjadi $121,1 \mathrm{kPa}$ untuk tanah dasar yang telah di stabilisasi oleh polimer dengan waktu curing 7 hari. Nilai modulus elastisitas juga mengalami kenaikan dimana tanah asli memiliki nilai modulus sebesar $823,7 \mathrm{kPa}$ dan tanah dicampur polimer dengan waktu curing 72 jam memiliki nilai sebesar 3139,1 kPa. Hasil uji kuat tekan bebas tidak signifikan karena hanya mengalami kenaikan sebesar $10 \%$. Kenaikan kuat tekan tanah yang tidak signifikan diprediksi akibat adanya kandungan organik yang ada dalam tanah.

\section{DAFTAR PUSTAKA}

AASHTO M145-91, 1991, Standard Specification for Classification of Soils and SoilAggregate Mixtures for Highway Construction Purposes, AASHTO Officials, Washington DC.

ASTM D422-63, 2010, Standard Test Method for Particle-Size Analysis of Soils, ASTM International, West Conshohocken, Pennsylvania.

ASTM D698-12e2, Standard Test Methods for Laboratory Compaction Characteristics of Soil Using Standard Effort (12 $400 \mathrm{ft}$-l $\mathrm{lff} / \mathrm{ft} 3(600 \mathrm{kN}-\mathrm{m} / \mathrm{m} 3))$, ASTM International, West Conshohocken, PA, 2012.

ASTM D854-02, 2010, Standard Test Method for Specific Gravity of Soil Solids by Water Pycnometer, ASTM International, West Conshohocken, Pennsylvania.

ASTM D2166-00, 2010, Standard Test Method for Unconfined Compressive Strength of Cohesive Soil, ASTM International, West Conshohocken, Pennsylvania.

ASTM D2216-98, 2010, Standard Test Method for Laboratory Determination of Water (Moisture) Content of Soil and Rock by Mass, ASTM International, West Conshohocken, Pennsylvania.

ASTM D2487-00, 2010, Standard Practice for Classification of Soils for Engineering Purposes (Unified Soil Classification System), ASTM International, West Conshohocken, Pennsylvania.

ASTM D2488-00, 2010, Standard Practice for Description and Identification of Soils (Visual-Manual Procedure), ASTM International, West Conshohocken, Pennsylvania.Sauceda M., Johnson D.W., Huang J., Shafique S.B., Sponsel V.M., and Appleford M., 2014, Soil-Strength Enhancements from Polymer-Infused Roots, Journal of Geotechnical and Geoenvironmental Engineering, vol.140

ASTM D4318-00, 2010, Standard Test Method for Liquid Limit, Plastic Limit, and Plasticity Index of Soils, ASTM International, West Conshohocken, Pennsylvania.

Ates, 2013, The Effect of Polymer-Cement Stabilization on the Unconfined Compressive Strength of Liquefiable Soils, International Journal of Polymer Science. 
Georgees R.N., Hassan R.A., Evans R.P., and Jegatheesan P., 2018, Resilient Response Characterization of Pavement Foundation Material Using a Polyacrylamide-Based Stabilizer, ASCE Journal of Materials in Civil Engineering, vol.30, no.1.

Iyengar S.R., Masad E., Rodriguez A.K., Bazzi H.S., Litte D., and Hanley H.J.M., 2013, Pavement Subgrade Stabilization Using Polymers: Characterization and Performance, ASCE Journal of Materials in Civil Engineering, vol.24, no.4, pp. $472-483$

Kolay P.K., Dhakal B., Kumar S., and Puri V.K., 2016, Effect of Liquid Acrylic Polymer on Geotechnical Properties of Fine-Grained Soils, International Journal of Geosynthetic and Ground Engineering.vol.2,no.29.

Moustafa A.B., Bazaraa A.R., and Nour El Din A.R., 1981, Soil Stabilization by Polymeric Materials, Macromolecular Materials and Engineering, vol.97.

Naeni, S.A., and Ghorbanalizadeh, M., 2010, Effect of Wet and Dry Conditions on Strength of Silty Sand Soils Stabilized with Epoxy Resin Polymer, Journal of Applied Sciences, vol.10, no.22, pp. 2839-2846.

Naeni S.A., Naderinia B., and Izadi E., 2012, Unconfined Compressive Strength of Clayey Soils Stabilized with Waterborne Polymer, KSCE Journal of Civil Engineering, vol. 16,no. 6, pp. 943-949.

Rodriguez A.K., Ayyavu C., Iyengar S.R., Bazzi H.S., Massad Eyad., Little Dallas., and Hanley Howard J.M., 2018, Polyampholyte Polymer As a Stabiliser for Subgrade Soil, International Journal of Pavement Engineering, vol.19,no. 6, pp. 467-478.

Timoney, M.J., McCabe B.A., and Bell A.L., 2012, Experiences of dry soil mixing in highly organic soils, Proceedings of the Institution of Civil Engineers Ground Improvement, vol.165, pp. 3-14.

Wilkinson, A., Haque, A., and Kodikara J., 2010, Stabilisation of clayey soils with industrial by-products:part A, Proceedings of the Institution of Civil Engineers Ground Improvement, Issue G13, pp. 149-163. 